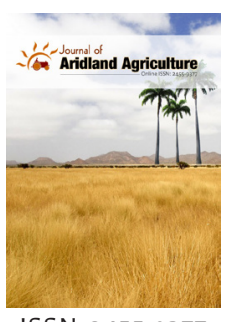

ISSN: $2455-9377$

\title{
Application of geographic information systems in effective management of the land resources of Syrdarya region, Uzbekistan
}

\author{
Kuziev R.K., Arabov S.A., Bobomurodov Sh. M., Baxodirov Z.A.* \\ Research Institute of Soil Science and Agrochemistry, Tashkent, Uzbekistan
}

Received: November 24, 2020

Revised: July 08, 2021

Accepted: July 09, 2021

Published: July 23, 2021

*Correspending Author:

Baxodirov Zafar

Abduvalievich

E-mail: zafarbahodirov@

gmail.com

\begin{abstract}
The article analyzes the opportunities of effective land management using geographical information systems. The perspectives of the using of geo information systems in the efficient use of agricultural lands especially in the development of recommendations for improving the reclamation of saline soils are given. The development of algorithms for the provision of relevant regulatory recommendations on the state of the lands in the studied area and the creating of salt washing norm maps based on GIS technologies have been studied.
\end{abstract}

KEY WORDS: soil quality condition, soil salinity, salt washing norms, geo information systems, geostatistics analysis.

\section{INTRODUCTION}

Today agricultural production and provision of food to the population are one of the most pressing issues in the world. This is due to the high increase of the world population, various environmental problems (land degradation and soil erosion, quantitative and qualitative changes in water resources, climate change) and many other socio-economic issues. Agricultural lands are key component of the ecological system of our earth that is closely linked to other parts of nature, such as water, forest, animal and plant world, minerals and other underground resources. Without lands and soils, other natural resources cannot be used. Therefore, as a result of non-efficient use of lands, the entire environment can be damaged in the immediate and future, which can lead to degradation of not only the surface layer also to problems of soil degredation, their erosion, soil salinity, water logging, chemical and radioactive contamination and environmental degradation.

Application of advanced technology to address land degradation problems remains a topical issue. One of the topical issues of today is the use of information and communication technologies in the field, effective management and monitoring of agricultural enterprises based on them. In particular, there is a need for an information system that provides storage, processing and delivery of data at different levels and levels in the field of effective land and soil resources management. By developing such systems, the field data can be easily evaluated, stored, updated and analyzed in terms of using and storing land resources. In the 1970s and 1980s, the first attempts were made to describe the spatial patterns of soil properties by interpolating (Burrough et al., 1994), attempts were made to determine the characteristic scales of spatial variation of soil cover and the size of soil individual (Kozlovsky, 1970), aerospace methods were developed for studying soil (Andronikov, 1990). The concept of the structure of the soil cover (Fridland, 1972) was actively developed in Russian soil science, which later became the basis for digital soil mapping.

In 1992, the "pedometrics" direction was formed as a separate branch of soil science, which deals with the use of mathematical and statistical methods for studying the distribution and genesis of soil (Meshalkina, 2012). Already in the 90s, ideas were expressed about the need to specify models for carrying out soil surveys (Hewitt, 1993), including models based on expert knowledge (Bui, 2004). At the end of the $20^{\text {th }}$ century a great number of knowledge was obtained in application of the methods of geostatistics in ecology and soil science (Isaaks et al., 1989).

The development of computer technology has led to the emergence of a new trend in soil cartography - digital soil mapping (DSM) (McBratney et al., 2003). Digital soil mapping is the creation and computer production of soil spatial information systems using numerical modeling of spatial and

Copyright: $\odot$ The authors. This article is open access and licensed under the terms of the Creative Commons Attribution License (http://creativecommons.org/licenses/by/4.0/) which permits unrestricted, use, distribution and reproduction in any medium, or format for any purpose, even commercially provided the work is properly cited. Attribution - You must give appropriate credit, provide a link to the license, and indicate if changes were made. 
temporal variability of soils and their properties based on field survey data and on soil formation factors (Mendonça et al., 2010). The methods of DSM are based on the models, which were developed on the basis of the factors of soil formation (Florinsky, 2012).

\section{MATERIAL AND METHODS}

\section{General}

Syrdarya region of the Republic of Uzbekistan is located at $40^{\circ} 25^{\prime}$ north latitude and $68^{\circ} 40^{\prime}$ east longitude. This region borders with the Republic of Kazakstan in the north, in the east with Tashkent region, in the south with the Republic of Tadjikistan, in the west with Jizzakh region. Its relief is mainly undulating plain, and gets lower from the south to the northwest. Some parts of Mirzachul steppe is included to the region. The northern parts are $230 \mathrm{~m}$, the central part is $400-450 \mathrm{~m}$, and the south and south-western parts are 600-650 $\mathrm{m}$ high [237; p. 407].

\section{Lands}

Syrdarya region is situated in the central part of the Mirzachul steppe and according to the administrative territorial division it is consisted of Boyovut, Gulistan, Mirzaobod, Oqoltin, Saykhunobod, Syrdarya, Khovos and Sardoba districts. Its total area is 4.276 thousand $\mathrm{km}$ square or 427.6 thousand ha, from them total irrigated lands make up 282.4 thousand ha (66\%) [238; p. 3]. The agriculture of the region is developed and multisectoral. Besides the valuable food and fodder plants (grain, maize, grapes, fruit, vegetables, melons and gourds, lucerne), main industrial plant - cotton is also takes main place in the agriculture of the region. As well as there are also a lot of livestock farms.

\section{Climate}

In common, the climate of the Mirzachul steppe is continental and subtropical. Changes of seasonal tropical and moderate air flow, increase of transpiration rate during the hot half of a year and the increase of Asian canal of the front of pole during the cold period of a year are the pecularities of this territory. That's why, in Uzbekistan, including Mirzachul, the summer is steady very hot and dry, and in the winter there is changeable weather. The territory of Sirdarya is open from the North-West and West, or from the site of wet and cold flow of air mass, and from the East and South it is enclosed by mountain chains, which highly effect on its temperature regime.

\section{Soils}

Territories with serozem-meadow and meadow soils, wide spread in Sirdarya region, were chosen as the object of the research. These soils (irrigated serozem-meadow and meadow) make up $76.6 \%$ of the land area on the soil genetic groups distributed in Sirdarya region.

\section{Irrigated Serozem-meadow Soil}

The lands of the key fields, in the massif Malik of Sirdarya district in Sirdarya region, consists of old irrigated serozemmeadow soils, formed in condition of 2-3 m depth of groundwater level. Before the cultivation and irrigation of these lands, they were considered as the developed derivative of light serozem soils in half hydromorphic condition after irrigation. Nowadays, in condition of increased hydromorphism they can change into meadow soils. Still, there is left the residual signs of light serozem soils in the profile of these soils.

\section{Irrigated Meadow Soils}

In the lands of the selected key fields, in the massif Gulistan of Sayhunobod district, old irrigated meadow soils were formed, in condition of 1-2.0 m depth of groundwater level. As these soils formed in the hydromorphic condition with high groundwater level to the earth surface, they are under the influence of permanent or periodical capillary moistening from the groundwaters. Therefore, in the lower horizons of the soil anaerobic conditions occur, and oxides of iron aluminium and manganese appeared in these layers and has dark-grey colour. Two key areas from the territories with serozem-meadow and meadow soils were chosen in Sirdarya region. The first key area is located in the irrigated serozem-meadow soils in the territory of massif "Malik" in Sirdarya district of Sirdarya region. The area is 200 ha. The second key area is located in the irrigated meadow soils in the territory of massif "Guliston" in Sayhunobod district of Sirdarya region. The area is 200 ha.

Coordinates - geographical location of the chosen observation sites were marked with the instrument "GPS Garmin ETrex-60". The areas are located 250-300 $\mathrm{m}$ above the sea level and the difference between them is 0056'413" on the north latitude, 0013'36" on the east longitude and absolute height with $50 \mathrm{~m}$. Methods as comparative-geochemical, comparativegeographical, laboratory-analytical, data accumulation, spatial analysis and modeling on the base of geo-informational systems make up the fundaments of the research methods. Soil samples were taken from serozem-meadow soils in the area. The location of the soil samples was recorded using modern GPS equipment. Field surveys were carried out on the basis of "Instruction on soil survey and soil mapping for the State Land Cadastre". Mechanical content (texture) of soils was analyzed by the pipette method of N.A. Kachinsky. Amount of salts and ion content in the soil were analyzed using aqueous absorption method, degree and chemistry (type) of salinity - by L.P.Lebedev methods. Geographic information system analyzes were carried out using ArcGIS 10 software and its Geostatistical Analyst modules.

\section{RESULTS AND DISCUSSION}

\section{Soil Texture in the Key Fields}

Texture of soil has considerable influence on its number of characteristics, i.e. on physical, physical-chemical, chemical, 
agrochemical, biological and other characteristics of soil. In particular, water-holding capacity of soil and ability of getting water from lower layers and its water transmitting depends on the texture of soil. Moreover, warmth characteristics and temperature regime; physic-mechanical characteristics; comparative strength of the soil against the agricultural machinery during cultivation; ripening dates, stickness, viscosity, soaking and sinking conditions are also connected with the texture of soil.

Irrigated meadow-serozem, serozem-meadow and soils, in the observed key fields of Sirdarya region, consist of light and heavy loamy texture, and some samples in the lower horizons of soil profile, change with the loamy and clay texture layers (Figure 1). The amount of physical clay $(<0.01 \mathrm{~mm})$ in the soils of these key fields fluctuates in a wide range, and makes up 16-18\% in the depositions (loams) with light texture, 21-30\% in light loams, 32$45 \%$ in medium loams and $45-58 \%$ in heavy loams, silt $(<0,001$ мм) fractions are in the amount between $1.4-3.3 \%$ and $13-16 \%$.

Texture of soils in the massif Malik in Sirdarya district differ from the texture of soils in other key fields, and here, the soil profile in the depth of $115-193 \mathrm{~cm}$ consist of residues of medium clay texture, amount of physical clay is 75.6-77.3; indications of silt fraction make up 18.1-19.4\% (Figure 2).

\section{Salinization Processes in Soils}

Condition of melioration of irrigated soils, their water-salt regimes have tight connection with a number of factors, as parameters of groundwater, soil solution concentration, irrigation regime, water quality for salt washing and irrigation, texture of soil, as well as geomorphologic and lithological structure of area and climate conditions. All factors, defining the salt regime of certain soil types, interrelate with each other, and changes within one of them cause to significant changes within several of them at the same time.
According to the data of the aqueous extract analysis of the irrigated soils of the chosen key fields, the total solid residues of salts in the ploughed and under ploughed layers of the light serozem soils, distributed in this area, is $0.175-0.199 \%$, and in lower layers it is $1.66-2.43 \%$. Salinity in these soils is mostly with sulphate and sulphate-chloride, according to the salinity level they are mostly included to the group of soils of less saline, medium saline and sometimes high saline. On the allocation of the amount of salted horizons in soil profile, alkali soil (including high and deep alkali soil) and saline groups, as well as salted profiles can be detected (Table 1).

\section{GIS Analysis of Soil Texture}

Soil texture defines various physical-chemical properties of soils. Consequently, the amount of physical clay in the content of soil is an important factor in defining soil fertility. Humus content, amount of nutrients and its physical-chemical properties change depending on soil texture. On the basis of obtained data, the distribution map of physical clay $(<0.01)$ in the ploughed layer of soil of the studied area was created with the method of interpolation, one of the methods of geospatial analyses (Figure 3).

\section{GIS Analysis of Soil Salinity}

It is known that, soil salinity is considered one of the main factors, which has negative influence on soil fertility. Soil salinity has negative impacts on the development of agricultural crops, and decreases harvest from them significantly. Soil salinity is one of the most urgent problems, in particular, in our research areas, and most parts of the irrigated lands of Sirdarya region is considered as less and medium saline soils.

In creating maps of the parameters of salinity block of soil fertility model, solid residues and amount of sulphate and chlorine salts were determined. Based on these indicators, soil salinity maps were created with GIS, by interpolation method (Figure 4).

Table 1: Amount of easily soluble salts in water and salinization chemism in the soils of the key fields in Sirdarya region

\begin{tabular}{|c|c|c|c|c|c|c|c|c|c|c|}
\hline \multirow[t]{2}{*}{$\begin{array}{l}\text { Soil profile } \\
\text { № }\end{array}$} & \multirow[t]{2}{*}{$\begin{array}{l}\text { Depth, } \\
\text { cm }\end{array}$} & \multirow{2}{*}{$\begin{array}{l}\text { Solid } \\
\text { residue } \\
(\%)\end{array}$} & \multicolumn{3}{|c|}{$\begin{array}{c}\text { Anions } \\
\text { (mg/equivalent) }\end{array}$} & \multicolumn{3}{|c|}{$\begin{array}{c}\text { Cations } \\
\text { (mg/equivalent) }\end{array}$} & \multicolumn{2}{|c|}{ Salinization } \\
\hline & & & $\mathrm{HCO}_{3}$ & $\mathrm{Cl}$ & $\mathrm{SO}_{4}$ & $\mathrm{Ca}$ & $\mathrm{Mg}$ & $\mathrm{Na}$ & Type & Degree \\
\hline \multirow{6}{*}{$\begin{array}{l}\text { KF 1, } \\
\text { Sirdarya district, massif } \\
\text { Malik, } \\
\text { Serozem-meadow }\end{array}$} & $0-30$ & 1,280 & 0,25 & 1,41 & 15,28 & 13,47 & 1,48 & 1,98 & $\mathrm{SO}_{4}-\mathrm{Na}-\mathrm{Ca}$ & Medium \\
\hline & $30-53$ & 1,175 & 0,30 & 1,98 & 15,03 & 13,72 & 1,48 & 2,09 & $\mathrm{SO}_{4}-\mathrm{Na}-\mathrm{Ca}$ & Medium \\
\hline & $53-83$ & 1,255 & 0,30 & 0,40 & 16,65 & 13,72 & 2,22 & 1,39 & $\mathrm{SO}_{4}-\mathrm{Mg}-\mathrm{Ca}$ & Medium \\
\hline & 83-119 & 0,705 & 0,25 & 0,40 & 8,55 & 7,24 & 1,73 & 0,23 & $\mathrm{SO}_{4}-\mathrm{Mg}-\mathrm{Ca}$ & Low \\
\hline & $119-159$ & 0,540 & 0,25 & 0,28 & 6,68 & 5,24 & 1,48 & 0,49 & $\mathrm{SO}_{4}-\mathrm{Mg}-\mathrm{Ca}$ & Low \\
\hline & $159-193$ & 0,665 & 0,30 & 0,59 & 7,97 & 6,24 & 1,48 & 1,14 & $\mathrm{SO}_{4}-\mathrm{Mg}-\mathrm{Ca}$ & Low \\
\hline \multirow{6}{*}{$\begin{array}{l}\text { KF 2, Sayhunobod district, } \\
\text { Massif Gulistan, } \\
\text { Meadow }\end{array}$} & $0-29$ & 1,785 & 0,25 & 3,55 & 19,87 & 15,22 & 1,73 & 6,73 & $\mathrm{SO}_{4}-\mathrm{Na}-\mathrm{Ca}$ & Medium \\
\hline & $29-44$ & 1,995 & 0,20 & 4,34 & 22,37 & 14,47 & 0,74 & 11,70 & $\mathrm{SO}_{4}-\mathrm{Na}-\mathrm{Ca}$ & Medium \\
\hline & $44-74$ & 1,570 & 0,25 & 2,96 & 17,79 & 10,98 & 1,73 & 8,30 & $\mathrm{SO}_{4}-\mathrm{Na}-\mathrm{Ca}$ & Medium \\
\hline & $74-96$ & 1,435 & 0,20 & 3,75 & 15,19 & 7,98 & 0,49 & 10,66 & $\mathrm{Cl}-\mathrm{SO}_{4}-\mathrm{Ca}-\mathrm{Na}$ & High \\
\hline & $96-120$ & 1,650 & 0,25 & 4,15 & 17,69 & 9,98 & 2,22 & 9,88 & $\mathrm{Cl}-\mathrm{SO}_{4}-\mathrm{Na}-\mathrm{Ca}$ & High \\
\hline & $120-160$ & 0,940 & 0,25 & 1,07 & 12,07 & 5,99 & 2,47 & 4,93 & $\mathrm{SO}_{4}-\mathrm{Na}-\mathrm{Ca}$ & Low \\
\hline
\end{tabular}




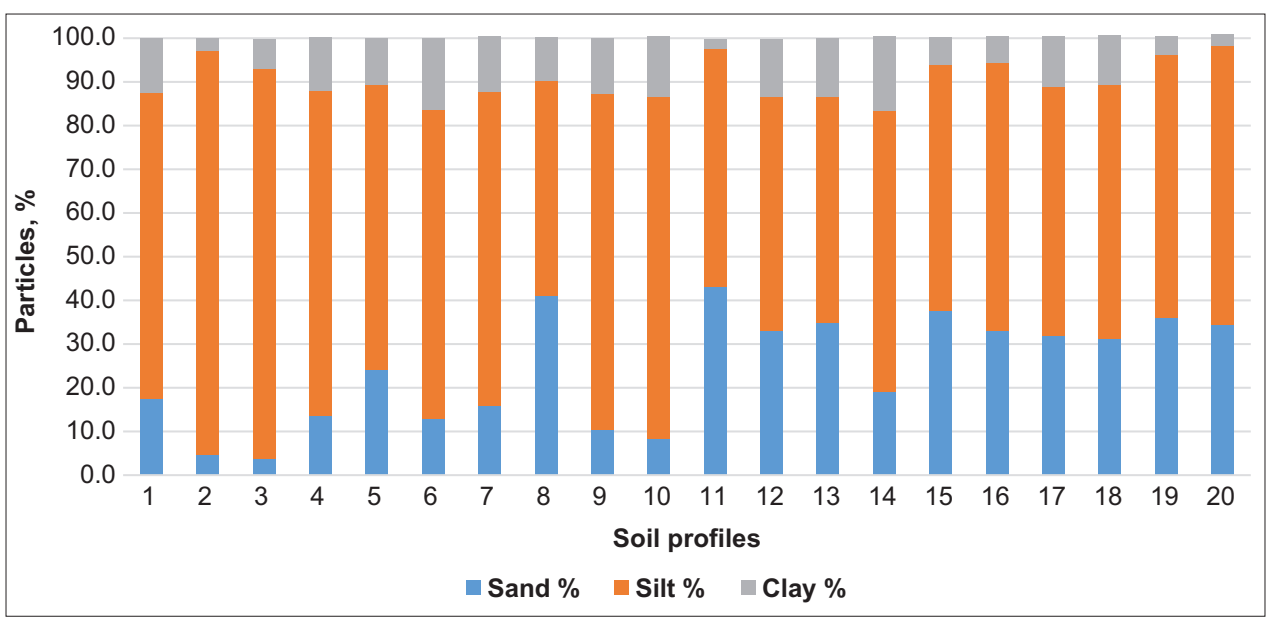

Figure 1: Distribution of soil particles in arable layer of irrigated serozem-meadow soils of the massif Malik of Sirdarya district in Sirdarya region

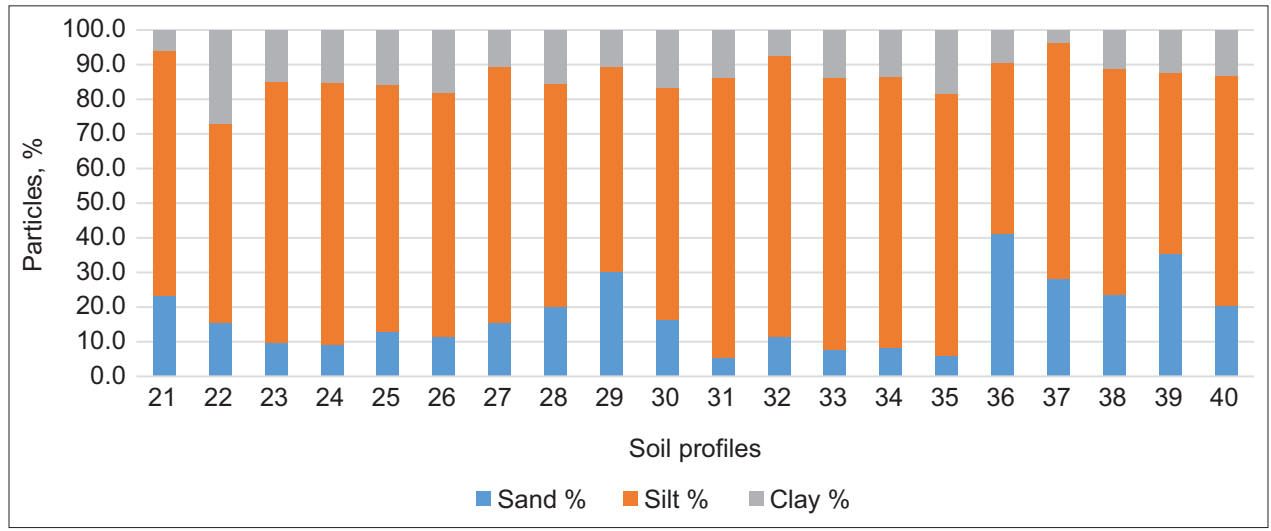

Figure 2: Distribution of soil particles in arable layer of irrigated meadow soils of the massif Guliston of Saykhunobod district in Sirdarya region

\section{GIS Analysis of Soil Leaching}

Fulfilling of the tasks as improving the melioration condition of irrigated lands, saving fertility, stabilizing and increasing, efficient use of lands requires to work out scientific based agromeliorative activities. These activities, of course, deals with soil properties, and soil salinity condition, amount of humus and nutrients in soil, agrophysical characteristics of soil should be taken into consideration. After studying these conditions on a scientific basis, relevant agromelioration, agrochemical, agrotechnical, and agrophysical activities will be determined and conducted. In our researches we have chosen factors as number and rate of irrigation, organic and mineral fertilizer rate and soil leaching rates and dates, which are considered as the main agromelioration activities. In working out these rates, the methods on the basis of generally accepted practical guides were used. After determining these rates, relevant GIS maps of them were created (Figure 5).

It is known that, soil salinity is considered one of the main factors, which has negative influence on soil fertility.
Soil salinity has negative impacts on the development of agricultural crops, and decreases harvest from them significantly. Soil salinity is one of the most urgent problems, in particular, in our research areas, and most parts of the irrigated lands of Sirdarya region is considered as less and medium saline soils.

In creating maps of the parameters of salinity block of soil fertility model, solid residues and amount of sulphate and chlorine salts were determined. Based on these indicators, soil salinity maps were created with GIS, by interpolation method.

In determination of soil salinity washing norms the study of soil salinity of territory is primarily taken into account. Because saline washing norms are formed in different groups in accordance with the conditions of different regions of our republic. For example, the Syrdarya region, which is engaged our research, is located in Jizzakh, Tashkent and Samarkand regions group. Once determined the region, the mechanical composition of the soils and the amount of chlorine ions are compared then differentiated to the relevant recommendation 


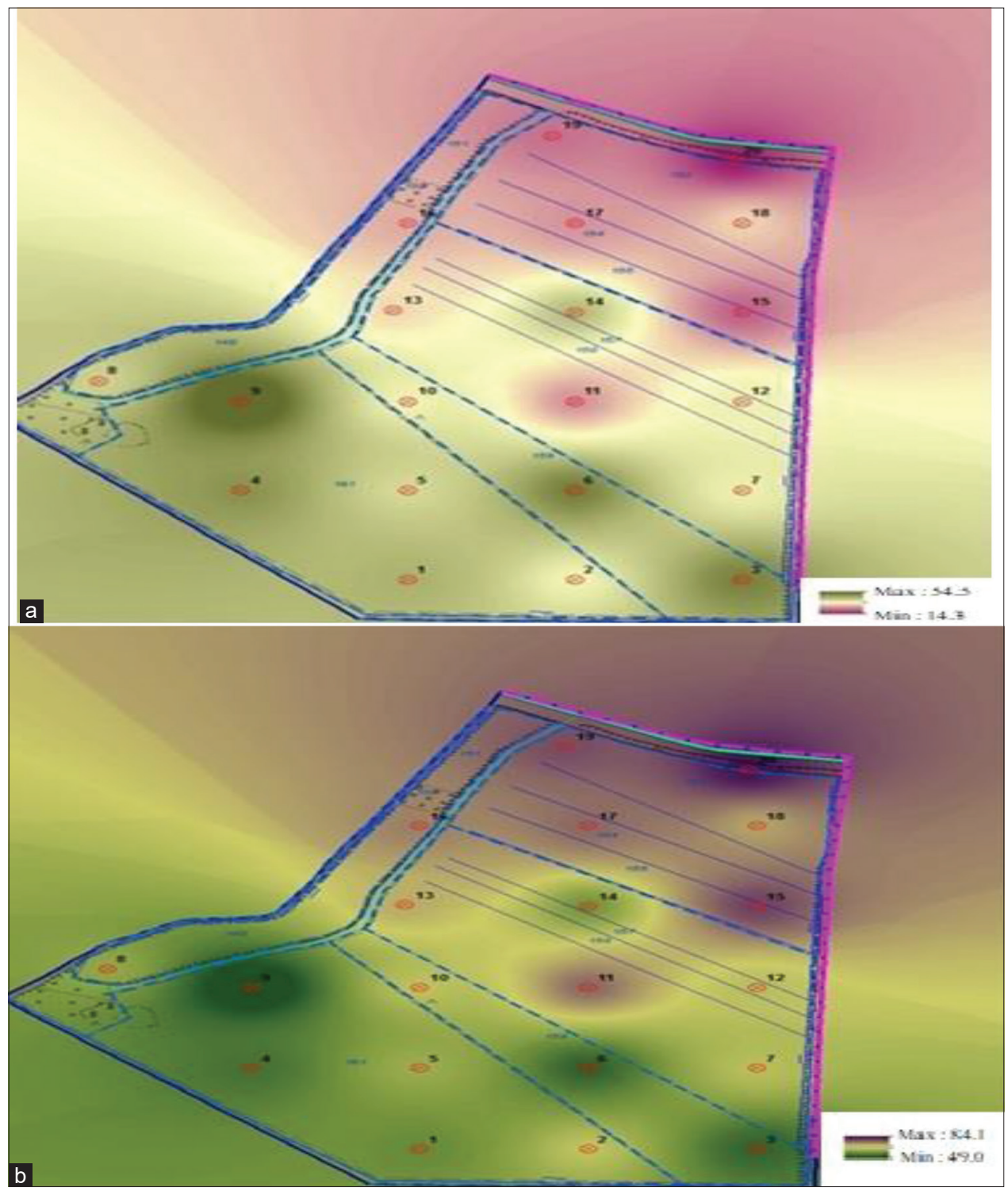

Figure 3: Texture maps of irrigated soils of the massif Malik of Sirdarya district in Sirdarya region: a -physical clay b - physical sand

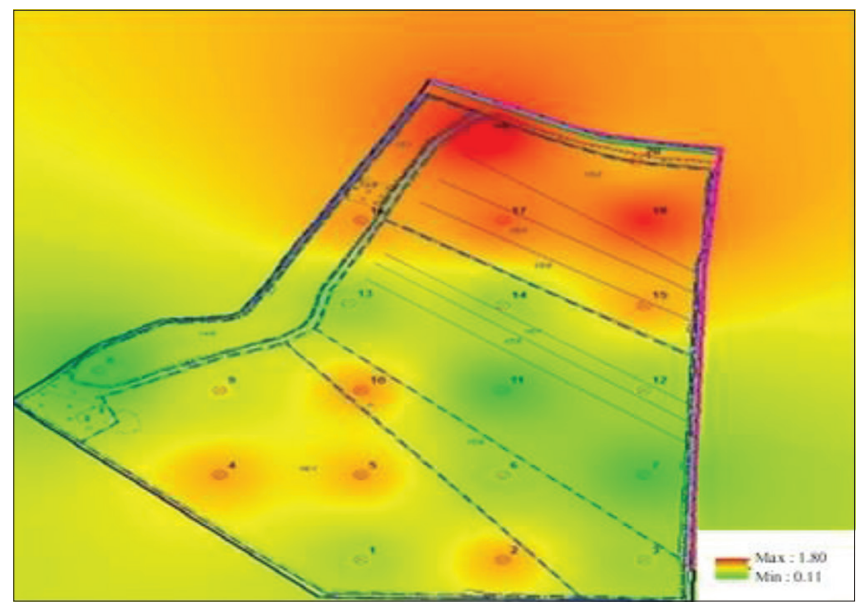

Figure 4: Soil salinity maps of the irrigated soils of the massif Malik of Sirdarya district in Sirdarya region (solid residues) groups. For example, if the soil in Syrdarya region is medium and light loamy according to the mechanical composition, and chlorine ion concentrations are in the range of 0.01-0.04, salt washing norms as follows:

Common salt washing norms - 3000-3500 m2

Number of salt washes -1

Period of salt washing - October-December.

After the above salinity parameters have been identified according to soil salinity and at the next stage spatial analyzes were performed using a several indicators. At the same time, a map of soil salinity washing norms for the territory has been created, based on the soil mechanical composition and the amount of $\mathrm{Cl}$ salts. 


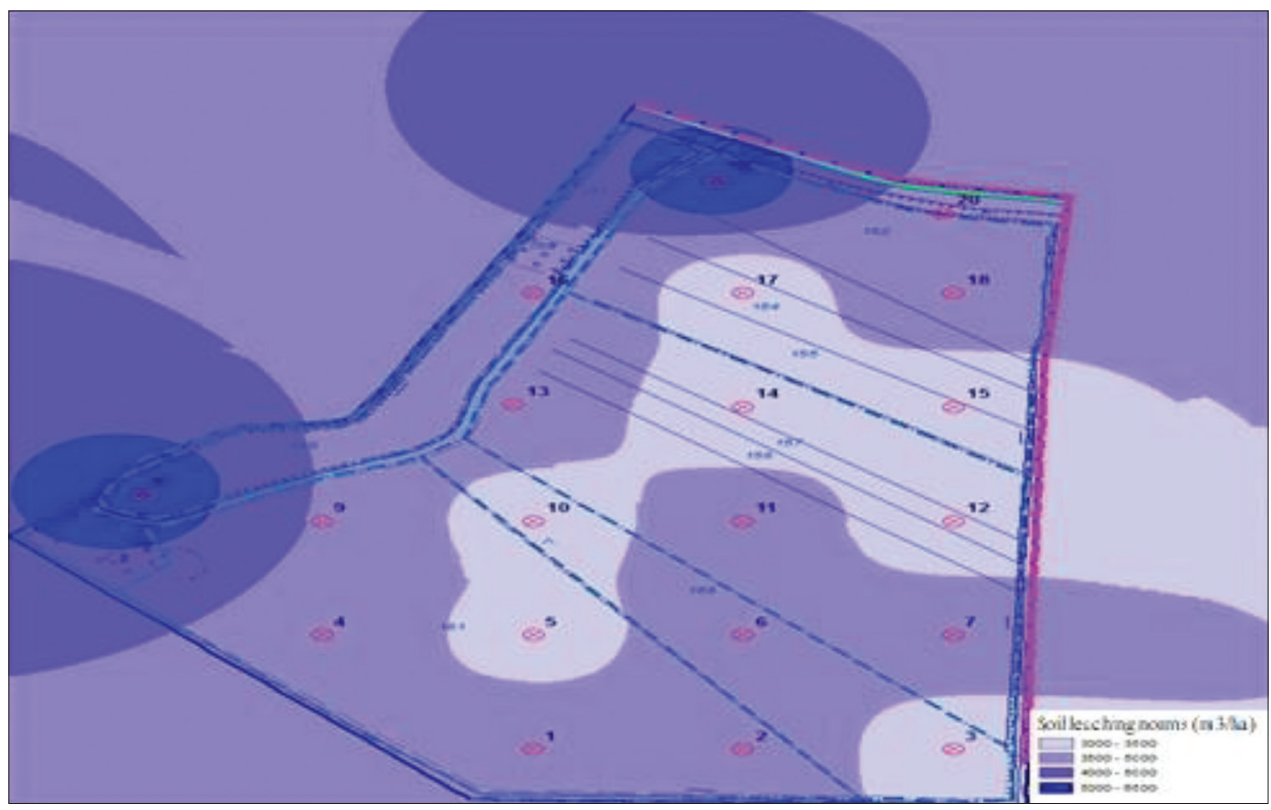

Figure 5: Maps of soil leaching activities for the massif Malik of Sirdarya district in Sirdarya region

\section{CONCLUSIONS}

As a result of the research, a wide range of opportunities for researchers to create thematic maps based on the soil research results using Spatial Analyst and Geostatistical Analyst modules of ArcGIS software are determined. In summary, it should be noted that the use of modern geoinformation technologies in the effective management of land resources can provide accurate and timely information, increase their operational processing and storage capacity, and creating relevant database will ultimately provide an excellent analysis of the state of the land resources. The thematical digital maps developed using geospatial analysis in the geographical information systems, illustrated its agroecological conditions, soil properties and relevant agro-meliorative measures for the studied areas recommended as a scientific basis for the placement of agricultural crops, calculating the land value, and determining crop yields. GIS is an effective tool for mapping, creating database, spatial description of soil cover. Because of this, GIS very powerful tool for planning and organizing land management practices in agricultural areas. This is especially true for aridland agriculture. In aridland agriculture, saving water resources used for agricultural use is very important. Our studies show that using modern GIS technologies help saving water resources based on soil properties. Organizing soil-leaching activities based on spatial description of soil mechanical content, soil salinity degree and type improves soil-leaching practices, which eventually helps to save water resources in aridland agriculture. In order to efficiently manage soil fertility, it is recommended to apply a complex of measures that improve soil fertility - systems for the graduated application of mineral and organic fertilizers at optimal rates and soil washing in saline soils based on spatial distribution of soil propoertis.

\section{REFERENCES}

Andronikov, V.L. (1990). Aerospace methods in soil science and their use in agriculture. Moscow, USSR: Nauka.

Bui, E. N. (2004). Soil survey as a knowledge system. Geoderma. https:// doi.org/10.1016/j.geoderma.2003.07.006

Burrough, P., Bouma, J., and Yates, S. (1994). The state of the art in pedometrics. Geoderma. https://doi.org/10.1016/00167061(94)90043-4

Florinsky, I. V. (2012). Dokuchaev's hypothesis as the basis for digital predictive soil mapping. Pochvovedenie, 4, 500-506.

Fridland, V. M. (1972). The structure of the soil cover. Moscow, USSR: Misl.

Hewitt, A. E. (1993). Predictive modelling in soil survey. Soils and Fertilizers, 56, 305- 314.

Isaaks, E. H., and Srivastava, R. M. (1989). An Introduction to Applied Geostatistics. - New York, USA: Oxford University Press.

Kozlovsky, F. (1970). Soil individual and methods of its determination. In M.A. Glazovskaya, E.A. Dmitiriev (Eds.), Patterns of spatial variation in soil properties and information and statistical methods of study. (pp 42-59) Moscow, USSR: Nauka.

McBratney, A. B., Mendonça, M. L., and Minasny, B. (2003). On digital soil mapping. Geoderma. https://doi.org/10.1016/S0016-7061(03)00223-4

Mendonça, M. L., Dart, R. O., Santos, H. G., Coelho, M. R., Berbara, R. L., and Lumbreras, J. F. (2010). Digital soil mapping of topsoil organic carbon content of Rio de Janeiro State, Brazil. In J. L. Boettinger, D. W. Howell, A. C. Moore, A. E. Hartemink, and S. K. Brown (Eds.), Digital Soil Mapping (pp. 255-266) New York, USA: Springer Science + Business Media B.V. https://doi.org/10.1007/978-90-481-8863-5 21

Meshalkina, Yu. L. (2012). What is digital soil mapping? (review) In Ivanov, A. L (Eds.). Digital soil cartography: theoretical and experimental research. (pp 9-18) Moscow, Russian Federation: Soil research institute named after V.V. Dokuchaev Publishing. 